\title{
In situ light spectroscopy in the environmental transmission electron microscope (ETEM)
}

Cavalca, Filippo; Langhammer, C.; Pedersen, Thomas; Dahl, S.; Wagner, Jakob Birkedal; Hansen, Thomas Willum

\author{
Published in: \\ EMC2012 proceedings
}

Publication date:

2012

Document Version

Publisher's PDF, also known as Version of record

Link back to DTU Orbit

Citation (APA):

Cavalca, F., Langhammer, C., Pedersen, T., Dahl, S., Wagner, J. B., \& Hansen, T. W. (2012). In situ light spectroscopy in the environmental transmission electron microscope (ETEM). In EMC2012 proceedings http://Link to proceedings

\section{General rights}

Copyright and moral rights for the publications made accessible in the public portal are retained by the authors and/or other copyright owners and it is a condition of accessing publications that users recognise and abide by the legal requirements associated with these rights.

- Users may download and print one copy of any publication from the public portal for the purpose of private study or research.

- You may not further distribute the material or use it for any profit-making activity or commercial gain

- You may freely distribute the URL identifying the publication in the public portal 


\title{
In situ light spectroscopy in the environmental transmission electron microscope (ETEM)
}

\author{
F Cavalca $^{1}$, C Langhammer ${ }^{2}$, T Pedersen $^{3}$, S Dahl $^{4}, \mathrm{~J} \mathrm{~B} \mathrm{Wagner}^{1}$, T W Hansen $^{1}$ \\ 1. Center for Electron Nanoscopy, Technical University of Denmark, DK-2800 Kgs. Lyngby, Denmark \\ 2. Chemical Physics, Chalmers University of Technology, SE-41296 Göteborg, Sweden \\ 3. Department of Micro- and Nanotechnology, Technical University of Denmark, DK-2800 Kgs. Lyngby, \\ Denmark. \\ 4. Center for Individual Nanoparticle Functionality, Technical University of Denmark, DK-2800 Kgs. Lyngby, \\ Denmark.
}

filippo.cavalca@cen.dtu.dk

Keywords: ETEM, LSPR, catalysis

Photocatalysts are of fundamental interest for sustainable energy research [1]. By means of transmission electron microscopy (TEM), insight into the structure and composition can be obtained and used for their further optimization [2]. Here, we combine conventional TEM analysis on photocatalysts with several in situ TEM techniques including environmental transmission electron microscopy (ETEM) $[3,4]$, in situ photo activation and localized surface plasmon resonance (LSPR) spectroscopy $[5,6]$.

ETEM is a well-established technique for material analysis. In this work we implement indirect nanoplasmonic sensing (INPS) [5] in an ETEM using a unique platform that allows simultaneous TEM imaging and optical spectroscopy under the same conditions. TEM and INPS work in a synergistic way since TEM is able to probe matter on a local scale and INPS is a spectroscopic technique that collects and integrates the LSPR signal coming from the whole specimen, providing information complementary to the TEM analysis. During any ETEM experiment the electron beam effect on the sample is a difficult issue to address and rule out. In addition, if a reaction has to be followed in situ in the ETEM, the information is often recorded on a limited portion of the sample. Being able to probe the sample with INPS and ETEM at the same time allows parallel investigation at the local and macro scale, as well as aids the assessment of beam effects.

A dedicated custom TEM specimen holder containing two optical fibers, five electrical contacts, a fixed miniaturized optical bench for light handling and a heating element (Fig. 1) has been designed. A system of pre-aligned mirrors and a MEMS heater are implemented in the holder.

The system is primarily designed for use in combination with LSPR spectroscopy, but it is flexible and can be employed with a variety of other methods that require light input and/or output. The two fibers can be used as parallel light inlets to activate a photoinduced reaction, e.g. photoinduced reduction of particles or nanoparticle photodeposition [7]. Alternatively, both fibers can be used to capture cathodoluminescence or other optical signals from the sample during electron irradiation.

In order to further support the information acquired in situ, a custom-made vacuum chamber equipped with gas inlets and outlets, optical feedthroughs, mass spectrometer and a port for TEM holder insertion was developed (Fig. 2). Bridging the gap between the ex situ INPS system and the ETEM is thus possible.

In this work the first results obtained using the combined TEM-INPS system are shown and compared to reference experiments acquired in ex situ INPS reactors. 


\section{References}

[1] J M Herrmann, Topics in Catalysis 34 (2005), p. 49-65.

[2] M Tsujimoto, S Moriguchi, S Isoda, et al. Journal of Electron Microscopy 48 (1999), p. 361-366.

[3] ] T W Hansen, J B Wagner, R E Dunin-Borkowski, Materials Science and Technology 26 (2010), p. $1338-1344$.

[4] E D Boyes, P L Gai, Ultramicroscopy 67 (1997), p. 219-232.

[5] E M Larsson, C Langhammer, I Zorić, B Kasemo, Science 326 (2009), p. 1091-4.

[6] C Langhammer, E M Larsson, B Kasemo, et al., Nano Letters 10 (2010), p. 3529-3538

[7] F Cavalca, A B Laursen, B E Kardynal, et al., Nanotechnology 23 (2012), p. 075705

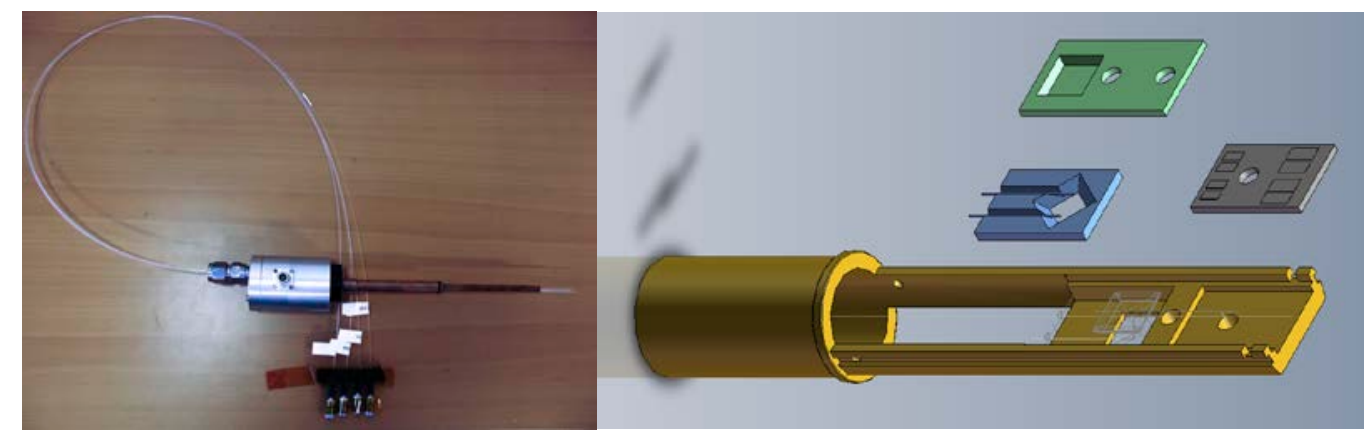

Figure 1. (Left) Photograph of the specimen holder shown without a tip for ease of visualization [7]. (Right) Schematic drawing of the specimen holder tip, including the mirror chip (blue), the heater (green) and the contact pad (grey).

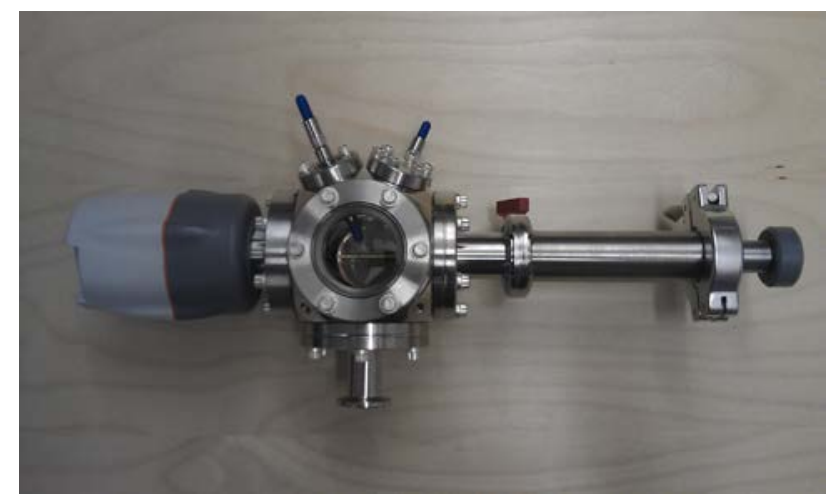

Figure 2. The ex situ INPS-TEM reactor. The system is shown with a TEM holder inserted, the pressure gauge and optical ports. 